\title{
Valores Organizacionais e Civismo nas Organizações
}

\author{
Juliana Barreiros Porto \\ Álvaro Tamayo
}

\section{Resumo}

Constitui objetivo deste estudo investigar os tipos motivacionais de Valores Organizacionais que se relacionam com os comportamentos de civismo nas Organizações. Participaram do estudo 458 funcionários de quatro organizações, sendo duas empresas públicas, uma privada e uma cooperativa. Os participantes responderam ao Inventário de Valores Organizacionais e à Escala de Civismo nas Organizações, além de dados pessoais. Foram realizadas análises descritivas e regressão múltipla padrão. Os resultados indicam que valores organizacionais predizem os comportamentos de civismo nas organizações. O pólo Autonomia apresentou-se como preditor dos cinco comportamentos de civismo. Ele refere-se aos valores de inovação e expressa características de organizações que estimulam a inovação e a criatividade. Outros pólos que se apresentaram como preditores foram: Harmonia, Domínio e Hierarquia. O presente trabalho aponta para a cultura organizacional como uma importante variável para os estudos dos comportamentos de civismo.

Palavras-chave: valores organizacionais; civismo nas organizações; cidadania organizacional.

\begin{abstract}
The objective of the present article was to explore the organizational values that predict Organizational Civism. The data was obtained from a sample of 458 employees of four organizations: two publics' organizations, one private and one co-operative. Respondents completed the Organizational Values Inventory, the Organizational Civism Scale and background questions. The analysis used was descriptives and standard multiple regression. The results indicated Organizational Values as predictors of Organizational Civism behaviors. Autonomy was predictor of the five Civism behaviors. It represents values of innovation and express features of organizations that stimulate innovation and creativity. Harmony, Mastery and Hierarchy were also predictors of Organizational Civism. The present study indicates organizational culture is an important variable for the comprehension of Organizational Civism Behaviors.
\end{abstract}

Key words: organizational values; organizational civism; organizational citizenship. 


\section{INTRODUÇÃO}

Katz e Kahn (1974) afirmam que organizações que se baseiam exclusivamente no papel prescrito possuem uma estrutura extremamente frágil. Segundo eles, o comportamento inovador e espontâneo é necessário para a organização, já que ele constitui um "desempenho acima dos requisitos de papel para a consecução das funções organizacionais” (p. 381). Eles descrevem este comportamento por meio dos seguintes elementos:

1. Atividades de cooperação com os demais membros da Organização.

2. Ações protetoras ao sistema ou subsistema.

3. Sugestões criativas para melhoria organizacional.

4. Autotreinamento para maior responsabilidade organizacional.

5. Criação de clima favorável para a Organização no ambiente externo.

Este tipo de comportamento é de capital importância para a sobrevivência da organização e o trabalho de Podsakoff, Ahearne e MacKenzie (1997) aponta a importância desta variável na predição do desempenho do trabalho em equipe. Esses autores encontraram que os comportamentos de civismo nas organizações têm efeito positivo para o desempenho do trabalho. Assim, a compreensão destes comportamentos torna-se fundamental para um melhor gerenciamento do desempenho das pessoas. Além disso, os estudo sobre os comportamentos de civismo nas organizações têm recebido grande atenção, já que as conseqüências dos comportamentos extrapapel são amplificadas em ambientes competitivos aliados à tecnologia computacional. "Se por um lado o enorme capital gasto em tecnologia requer uma utilização ótima dos investimentos tecnológicos, por outro lado, tecnologias computacionais intensivas tornam as organizações mais vulneráveis à agressão de funcionários na forma de sabotagem computacional" (NORD; FOX, 1996, p. 161). Assim, funcionários que apresentam comportamentos de civismo evitariam esse tipo de agressão.

Nord e Fox (1996) apontam ainda que, apesar de tradicionalmente o centro de interesse dos estudiosos das organizações sempre ter sido o indivíduo, observase atualmente um foco maior nas questões de contexto do que do indivíduo. Dentro dessa perspectiva, constitui objetivo deste trabalho teórico-empírico relacionar os valores organizacionais sobre os comportamentos de civismo nas 
organizações, identificando os valores organizacionais que predizem esses comportamentos.

Este artigo está estruturado da seguinte forma: a primeira parte apresenta a conceituação de civismo nas organizações; na segunda parte são revisados os principais artigos sobre os antecedentes de civismo; na terceira parte é apresentada a teoria de valores nas organizações; o método de pesquisa está descrito na quarta parte; na seqüência são apresentados e discutidos os resultados; na última parte apresenta-se a conclusão.

\section{Civismo nas Organizações}

Em 1983, Smith, Organ e Near (1983) denominaram de comportamentos de Cidadania Organizacional os comportamentos inovadores e espontâneos descritos por Katz e Kahn (1974). Este termo tem recebido críticas quanto à sua pertinência para denominar esses comportamentos (PORTO; TAMAYO, 2002; SIQUEIRA, 1995). Siqueira (1995) sugere a expressão Civismo nas Organizações depois de argumentar sobre a maior pertinência desse termo. Assim, optou-se neste trabalho pelo termo Civismo nas Organizações, pois o seu significado na linguagem comum é mais coerente com a definição dos comportamentos aqui apresentados do que Cidadania Organizacional.

Civismo nas organizações é definido como atos espontâneos dos trabalhadores que beneficiam o sistema organizacional. Este conceito é caracterizado, segundo Siqueira (1995), pela:

1. Espontaneidade, característica básica que diferencia Civismo nas Organizações dos outros atos delimitados pelo cumprimento do dever contratual.

2. Funcionalidade, garantia da natureza benéfica à organização.

3. Irrestrição, permissão de formas particulares de manifestação.

4. Isenção de retribuição prevista pelo sistema, comportamento de natureza social.

5. Caráter público das ações, possibilidade de observação por parte do sistema organizacional.

Vários são os antecedentes desses comportamentos apontados na literatura sobre comportamento organizacional. A seguir, são apresentados os principais resultados dessas pesquisas. 


\section{Determinantes do Civismo nas Organizações}

Com o objetivo de compreender os antecedentes de civismo nas organizações, os pesquisadores recorreram à Psicologia Social, devido ao caráter altruístico desses comportamentos. $\mathrm{O}$ foco inicial de estudos dos pesquisadores foi sobre o efeito de variáveis atitudinais e de personalidade sobre o civismo nas organizações.

Entre as variáveis atitudinais, satisfação no trabalho é a variável mais estudada e que tem apresentado relação positiva com os comportamentos de civismo (MUNENE, 1995; ORGAN; KONOVSKY, 1989; ORGAN; LINGL, 1995; SIQUEIRA, 1995; SMITH; ORGAN; NEAR, 1983; WITT; WILSON, 1990). Outros antecedentes investigados que apresentam relação positiva com civismo são: avaliação cognitiva dos resultados de trabalho (ORGAN; KONOVSKY, 1989), estado de humor positivo (GEORGE, 1991; GEORGE; BRIEF, 1992; ORGAN; KONOVSKY, 1989), internalização de valores organizacionais (O’REILLY; CHATMAN, 1986), comprometimento organizacional (O'REILLY; CHATMAN, 1986; SIQUEIRA, 1995; SHORE; WAYNE, 1993) e envolvimento com o trabalho (SIQUEIRA, 1995). Van Dyne, Cummings e Parks (1995) sugerem ainda como antecedentes atitudinais de comportamentos extrapapel a percepção de manutenção do contrato psicológico, a percepção de que as expectativas de justiça foram satisfeitas e a baixa alienação.

As variáveis de personalidade investigadas e que apresentam relação com os comportamentos de civismo são: neuroticismo e extroversão (SMITH; ORGAN; NEAR, 1983); a extensão em que as pessoas consideram seu trabalho seriamente e focam a energia nele (HUI; ORGAN; CROOKER, 1994); consciência ou grau de responsabilidade, confiança, persistência e organização de uma pessoa (ORGAN; LINGL, 1995); e, sentimento de responsabilidade (PEARCE; GREGERSEN, 1991).

Outra abordagem recorrente na literatura refere-se aos estudos sobre variáveis situacionais. As pesquisas sobre variáveis contextuais partem do princípio de que os comportamentos de civismo nas organizações se referem a trocas sociais baseadas na confiança de que a Organização é justa neste relacionamento; quando há a percepção de injustiça pode haver uma tendência, por parte do funcionário, em manter apenas aqueles comportamentos prescritos pelo papel, abolindo assim os comportamentos de civismo. As variáveis investigadas têm sido: justiça organizacional (MOORMAN, 1991; SKARLICKI; LATHAN, 1996; WITT; WILSON, 1990), suporte do líder (SMITH; ORGAN; NEAR, 1983), ideologia de troca (WITT, 1991), suporte organizacional (SHOR; WAYNE, 1993; SIQUEIRA, 1995; WITT, 1991), interdependência da tarefa (PEARCE; 
GREGERSEN, 1991), percepção de eqüidade (WITT; WILSON, 1990), troca líder-subordinado (SETTON; BENNETT; LIDEN, 1996; WAYNE; GREEN, 1993) e benefícios organizacionais (LAMBERT, 2000).

Organ e Ryan (1995) realizaram uma metanálise dos estudos de civismo nas organizações. Os artigos foram selecionados em quatro revistas científicas: Journal of Applied Psychology, Academy of Management Journal, Personnel Psychology e Organizational Behavior Human Decision Processes no período de 1983 a 1994. O modelo conceitual apresentado pelos autores sugere que as atitudes no trabalho e os fatores de personalidade são melhores preditores dos comportamentos de civismo nas organizações, em comparação com conhecimentos, habilidades e incentivos contratuais. Os resultados encontrados apóiam o modelo sugerido e apontam que: 1 - a satisfação se apresenta como melhor preditor de civismo do que justiça e comprometimento organizacional; 2 - as variáveis disposicionais apresentam um nível de associação com civismo menor que as variáveis atitudinais; 3 - o moderador mais forte das correlações das varáveis com civismo nas organizações é a auto-avaliação versus hetero-avaliação.

Buscando compreensão mais ampla desses comportamentos, Siqueira (1995) construiu um Modelo Teórico Pós-cognitivo para os antecedentes de comportamentos de civismo nas organizações que inclui atitudes e cognições. Seu modelo pressupõe que as atitudes relativas ao trabalho (satisfação no trabalho, envolvimento com o trabalho e comprometimento organizacional) são antecedentes diretos de comportamentos de civismo. E que as cognições (comprometimento organizacional calculativo, percepção de suporte organizacional e percepção de reciprocidade organizacional) são antecedentes das atitudes relativas ao trabalho.

Mais que as variáveis cognitivas, os resultados das regressões múltiplas evidenciaram que as variáveis afetivas apresentaram maiores proporções de variância explicada dos cinco fatores de civismo: criação de clima favorável à Organização, no ambiente externo; sugestões criativas ao sistema; proteção ao sistema; autotreinamento e cooperação com os colegas de trabalho. Para o fator Clima favorável à organização no ambiente externo, as variáveis comprometimento organizacional afetivo e envolvimento com o trabalho constituíram-se preditoras, mas não de satisfação no trabalho. Para Sugestões criativas, apenas comprometimento organizacional afetivo foi preditora, enquanto para Proteção ao sistema somente satisfação no trabalho. Para Autotreinamento, foram as variáveis envolvimento com o trabalho e satisfação no trabalho que contribuíram para explicar sua variância e para Colaboração com colegas, as variáveis comprometimento organizacional afetivo e envolvimento com o trabalho foram as preditoras. A autora conclui pela pertinência de seu modelo pós-cognitivo.

A partir de 1995, surge interesse pela influência dos valores pessoais sobre os 
comportamentos de civismo (MOORMAN; BLAKELY, 1995; PORTO; TAMAYO, 2002; TAMAYO; MUNIZ; DE OLIVEIRA; CARVALHO; MACEDO; ARMANDO; GUIMARÃES, 1998). Os estudos apontam que valores, tanto de motivações subjacentes sociocêntricas como individualistas, são preditores de comportamento de civismo. Esses resultados modificam a noção inicial de que comportamentos de civismo seriam puramente coletivistas.

Recentemente, alguns autores (PORTO, 1998; TAMAYO, 1996a) têm indicado que valores organizacionais podem ser preditores de civismo nas organizações, já que os valores formam a base da cultura organizacional e esta estabelece quais são os comportamentos esperados na organização.

Na área de valores organizacionais, alguns estudos foram realizados buscando relacionar valores organizacionais com comportamentos no trabalho (MEGLINO; RAVLIN; ADKINS, 1989; O’REILLY; CHATMAN; CALDWELL, 1991 apud WILPERT, 1995; SHERIDAN, 1992, apud WILPERT, 1995; TAMAYO, 1996). Apesar de os resultados terem apontado fraca relação entre eles, esta é uma área promissora, pois carece de bom instrumental e teorias consistentes.

Chatman (1991) sugere que a adequação entre valores individuais e organizacionais parece ser melhor preditor de satisfação com o trabalho, intenção de deixar a organização e rotatividade do que os valores individuais e valores organizacionais isoladamente. Este estudo indica que a adequação entre valores individuais e organizacionais são preditores úteis de atitudes e comportamentos dos indivíduos e, devem ser também, para os comportamentos de civismo.

Nos trabalhos encontrados que relacionam valores organizacionais e comportamento, porém, as escalas de valores organizacionais freqüentemente são ordinais e apresentam os mesmos problemas das pesquisas iniciais na área de valores e comportamento: (1) a fidedignidade é baixa, quando se busca compreender a relação entre um único valor e o comportamento; (2) falta uma teoria ampla de valores que permita a seleção de valores relacionados com o comportamento em estudo; (3) falha em compreender o pressuposto de que os comportamentos são guiados não apenas pela prioridade dada a um valor, mas pelas trocas entre valores conflitivos que estão simultaneamente implicados em um comportamento (SCHWARTZ, 1996).

A partir do desenvolvimento de uma teoria que permite superar os problemas lançados anteriormente, o campo de pesquisa se amplia e possibilita um avanço nessa área. Assim, constitui objetivo desse estudo investigar os tipos motivacionais de Valores Organizacionais que estariam relacionados com os comportamentos de civismo nas organizações, utilizando uma teoria recente de valores organizacionais desenvolvida por Tamayo (1996a) que será apresentada a seguir. 
cognitivo e motivacional, já que eles expressam formas de conhecer a realidade organizacional e servem para julgar e justificar o comportamento dos membros da organização. Os valores organizacionais expressam interesses e desejos de alguém, que pode ser do fundador, do dono, dos chefes ou de grupos (TAMAYO; GONDIM, 1996; TAMAYO, 1999). Os valores são representações cognitivas de três necessidades básicas das organizações: a primeira é lidar com a relação indivíduo-organização; a segunda é garantir comportamentos apropriados para a organização; e a terceira é estabelecer a relação entre a organização e o meio externo. Para Tamayo e Gondim (1996), a função dos valores é orientar a vida da organização e guiar o comportamento dos seus membros, delimitando a forma de agir, pensar e julgar das pessoas.

Tamayo (1996a) propõe um estudo dos valores organizacionais por meio da percepção dos funcionários, tendo como base teórica a Teoria dos Valores de Schwartz. Schwartz (1999) deriva tipos motivacionais que seriam respostas às necessidades básicas da sociedade. As três necessidades identificadas por ele são: (1) definir a natureza da relação entre indivíduo e sociedade; (2) garantir comportamentos responsáveis que preservem a fábrica social; (3) estabelecer a relação entre a humanidade e o mundo físico e social. As pesquisas de Schwartz (1992, 1994) têm demonstrado a validade universal desse modelo. Tamayo (1996a) propõe a transposição dessas necessidades para as organizações, formando assim uma estrutura dos valores organizacionais.

A primeira necessidade é a de estabelecer a natureza da relação entre indivíduo e grupo que origina a dimensão dos valores 'Conservadorismo X Autonomia'. No pólo do Conservadorismo, os interesses do indivíduo não são percebidos como diferentes dos do grupo e os valores enfatizam a manutenção do statu quo. No pólo da Autonomia, os valores expressam características de inovação e criatividade e a visão do empregado como entidade autônoma habilitada para perseguir seus próprios interesses. A Autonomia se subdivide em Autonomia Afetiva (valores de estimulação e hedonismo) e Autonomia Intelectual (valores de autodeterminação como criatividade e curiosidade).

O segundo problema a ser enfrentado diz respeito à forma de organização social que leva a dimensão 'Hierarquia X Igualitarismo'. A Hierarquia enfatiza a legitimidade de alocação de papéis e recursos. O Igualitarismo, por sua vez, ressalta a transcendência dos interesses individuais em favor do bem-estar organizacional.

A terceira e última questão imposta refere-se à relação entre as empresas (ou organizações) e o ambiente social e natural, sendo que as organizações podem optar por um dos pólos da dimensão 'Domínio X Harmonia'. As organizações dominadoras enfatizam valores que promovem o controle e a exploração do meio 
ambiente físico e social. No pólo oposto, os valores expressam uma adequação harmoniosa com o ambiente e outras organizações.

Desta forma, Tamayo (1996a) postula que os valores existentes nas organizações se organizam e estruturam em torno dessas três dimensões bipolares. Outro pressuposto do modelo é que existe relação dinâmica entre as dimensões, havendo compatibilidade e conflitos entre elas. A Figura 1 sintetiza essa teoria, apresentando os pólos motivacionais e representando as compatibilidades e conflitos por meio da proximidade e distância entre os pólos, respectivamente. A forma como essa relação se dá ainda precisa ser investigada.

\section{Figura 1: Estrutura dos Valores Organizacionais}

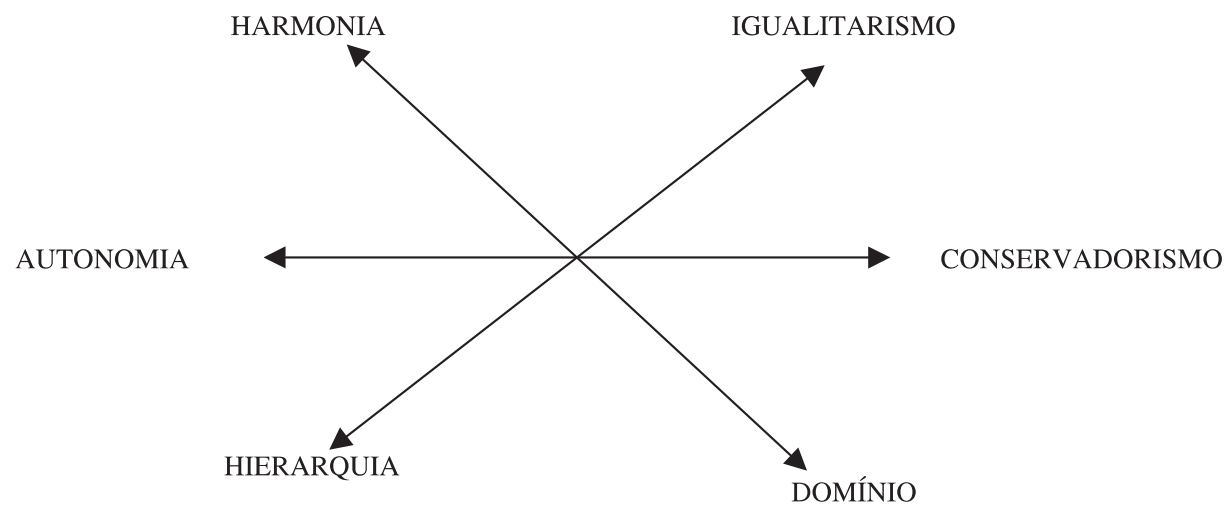

Fonte: Tamayo, 1996a.

Tamayo, Mendes e Paz (2000) desenvolveram e validaram por meio da análise fatorial uma escala para avaliar os valores organizacionais. Os resultados apoiaram a estrutura proposta teoricamente. Essa teoria permite avançar nos estudos que relacionam comportamento organizacional e valores organizacionais, por permitir maior fidedignidade, já que os instrumentos desenvolvidos são mais consistentes, e apresentar uma compreensão global do fenômeno que considera os fatores que são compatíveis e conflitivos com o comportamento. Assim, a seguir é descrito o método utilizado na pesquisa.

\section{A Pesquisa}

Para atingir os objetivos de pesquisa, foi utilizado o método correlacional, tendo como variáveis dependentes os cinco fatores de civismo e como variáveis independentes os fatores de Valores Organizacionais. 
Quatro empresas de diferentes tamanhos e áreas de atuação foram selecionadas para participar do estudo com o objetivo de ampliar a variabilidade dos valores organizacionais. Assim, participaram do estudo quatro empresas do Centro-Oeste, sendo duas empresas de médio porte: uma cooperativa médica e uma prestadora de serviços da área de saúde, e duas empresas de grande porte: uma organização bancária e uma organização governamental; 574 funcionários, distribuídos igualmente entre todas as empresas, responderam aos questionários. A amostra foi de conveniência; entretanto buscou-se contemplar os principais setores de cada organização. Desses participantes, 458 (80\%) foram aproveitados para análise; 116 foram eliminados, porque mais de 5\% dos itens não haviam sido respondidos. A média de idade foi de 34,14 com desvio-padrão de 8,59. A maioria dos funcionários (40,6\%) possuía de 1 a 5 anos de tempo de empresa; 51\% eram do sexo feminino; e $40 \%$ tinham curso superior completo, sendo que todos possuíam, pelo menos, curso médio completo.

Para coleta de dados, foi elaborado um questionário composto por duas escalas psicometricamente validadas e dados pessoais. As escalas estão descritas a seguir.

Escala de Civismo nas Organizações. Desenvolvida e validada por Porto e Tamayo (2003). Essa escala contém 41 itens que descrevem os comportamentos das pessoas no ambiente organizacional, como por exemplo: Quando alguém de fora fala mal desta organização, eu procuro defendê-la; Ofereço-me para substituir um colega que faltou ao trabalho; Apresento sugestões sobre novos produtos ou serviços que melhorem o funcionamento da organização. Cada item deve ser avaliado por meio de uma escala de freqüência de comportamentos, que varia de 1 (nunca) a 5 (sempre). A análise fatorial da escala, para a presente amostra, apontou os mesmos 5 fatores da validação realizada por Porto e Tamayo (2003): sugestões criativas ao sistema $(\alpha=0,92)$; proteção ao sistema $(\alpha=0,84)$; criação de clima favorável à Organização no ambiente externo $(\alpha=0,90)$; autotreinamento $(\alpha=0,81)$; e cooperação com os colegas $(\alpha=0,83)$.

Inventário de Valores Organizacionais. Desenvolvida e validada por Tamayo, Mendes e Paz (2000). Essa escala é composta por 36 itens que descrevem características organizacionais representativas dos diversos valores organizacionais, como, por exemplo: capacidade de inovar na organização; tradição e respeito às ordens; clima de ajuda mútua. Os participantes deviam avaliar os 36 itens conforme uma escala que variava de 0 (nada importante) a 6 (extremamente importante). A escala encontra-se dividia em 6 fatores: autonomia ( $\alpha=0,81)$; conservadorismo $(\alpha=0,78)$; hierarquia $(\alpha=0,88)$; igualitarismo $(\alpha=0,86)$; domínio $(\alpha=0,84)$; e harmonia $(\alpha=0,61)$.

Os questionários foram aplicados individualmente no local de trabalho dos 
participantes, sendo adotadas duas formas de coleta para se adequarem às demandas das organizações: (1) o questionário era enviado aos funcionários com uma carta explicativa; os funcionários deviam responder e depositar em uma urna ou encaminhar anonimamente a uma pessoa responsável na organização; (2) estudantes de Psicologia entregavam os questionários aos participantes, no próprio ambiente de trabalho, e recolhiam, em seguida, os questionários respondidos.

Para analisar os dados, foram realizadas análises descritivas e regressão linear padrão para cada fator da Escala de Civismo nas Organizações. A análise de regressão tem como principal objetivo investigar a relação entre uma variável dependente e variáveis independentes, detectando a força da relação e a importância de cada variável independente para a predição da variável dependente. Como no presente trabalho havia cinco variáveis dependentes, isto é, os cinco fatores de civismo nas organizações, foram realizadas cinco análises de regressão, uma para cada fator.

As análises preliminares de limpeza do banco de dados indicaram assimetria elevada para o fator Ações Protetoras; porém a transformação da variável não apresentou melhora significativa. Assim, optou-se por manter a variável sem transformação; porém é preciso alertar que este problema não invalida a análise, embora possa enfraquecer a relação. Casos extremos univariados foram detectados e eliminados $(\mathrm{n}=3)$. Com o uso do critério $\mathrm{p}<0.001$ para a distância mahalanobis, foram encontrados 7 casos extremos multivariados que foram eliminados. Após eliminação dos casos extremos, o banco ficou composto por 448 casos.

\section{Resultados}

Regressão múltipla padrão foi realizada para os fatores da variável dependente, civismo nas organizações; e os fatores da variável independente, valores organizacionais.

A tabela 1 apresenta os coeficientes de regressão (B), os coeficientes de regressão padronizados $(\beta)$, o $R, \mathrm{R}^{2}$ e $\mathrm{R}^{2}$ ajustado das regressões para os cinco fatores da escala de civismo. O R foi significativamente diferente de zero em todas as regressões, o que indica que os valores organizacionais são preditores importantes dos comportamentos de civismo nas organizações. Observa-se que os fatores Hierarquia, Domínio, Autonomia e Harmonia são preditores de, pelo menos, um fator de civismo nas organizações, sendo que Autonomia prediz todos os fatores. Os fatores Igualitarismo e Conservadorismo não se constituíram com preditores de civismo. 
Tabela 1: Resultados das Regressões Múltiplas para os Fatores da Escala de Civismo nas Organizações

\begin{tabular}{|c|c|c|c|c|c|c|c|c|c|c|}
\hline \multirow[t]{2}{*}{ VIs } & \multicolumn{2}{|c|}{$\begin{array}{l}\text { Sugestões } \\
\text { criativas ao } \\
\text { sistema }\end{array}$} & \multicolumn{2}{|c|}{$\begin{array}{c}\text { Ações } \\
\text { Protetoras }\end{array}$} & \multicolumn{2}{|c|}{$\begin{array}{c}\text { Clima } \\
\text { favorável no } \\
\text { ambiente } \\
\text { externo }\end{array}$} & \multicolumn{2}{|c|}{$\begin{array}{l}\text { Auto- } \\
\text { treinamento }\end{array}$} & \multicolumn{2}{|c|}{$\begin{array}{c}\text { Cooperação com } \\
\text { os colegas }\end{array}$} \\
\hline & $\mathrm{B}$ & $\beta$ & $\mathrm{B}$ & $\beta$ & $\mathrm{B}$ & $\beta$ & $\mathrm{B}$ & $\beta$ & $\mathrm{B}$ & $\beta$ \\
\hline Igualitarismo &,- 015 &,- 023 &,- 035 &,- 096 &,- 064 &,- 099 &,- 054 &,- 007 &,- 053 &,- 107 \\
\hline Conservadorismo & ,047 & ,069 & ,012 &, 031 & ,074 &, 110 & ,039 &, 047 &, 043 &, 084 \\
\hline Domínio & 045 &, 061 &,- 024 &,- 058 &, $137 * *$ & ,188 & ,009 &, 010 &, 075 & ,135 \\
\hline Hierarquia &,- 109 &, 058 &, $119 * *$ & ,304 &, 096 &, 140 &,- 017 &,- 020 &, 037 & 070 \\
\hline Autonomia &, $147 * *$ & ,229 & $0,054 *$ &, 151 & $.135 * *$ & .214 &, $117 *$ &, 152 &, $084 * *$ & ,175 \\
\hline Harmonia &, 059 &, 104 &,- 013 &, 017 &, 018 & ,032 &, $075^{*}$ &, 110 &, 017 &, 040 \\
\hline \multirow[t]{3}{*}{ Ajuste do Modelo } & \multicolumn{2}{|c|}{$R^{2}=., 074$} & \multicolumn{2}{|c|}{$R^{2}=, 096$} & \multicolumn{2}{|c|}{$R^{2}=, 245$} & \multicolumn{2}{|c|}{$R^{2}=, 059$} & \multicolumn{2}{|c|}{$R^{2}=, 113$} \\
\hline & \multicolumn{2}{|c|}{$R^{2} a j=, 062$} & \multicolumn{2}{|c|}{$R^{2} a j=, 084$} & \multicolumn{2}{|c|}{$R^{2} a j=, 235$} & \multicolumn{2}{|c|}{$R^{2} a j=, 047$} & \multicolumn{2}{|c|}{$R^{2} a j=, 100$} \\
\hline & \multicolumn{2}{|c|}{$R=, 273 * *$} & \multicolumn{2}{|c|}{$R=, 310^{* *}$} & \multicolumn{2}{|c|}{$R=, 495 * *$} & \multicolumn{2}{|c|}{$R=, 244 * *$} & \multicolumn{2}{|c|}{$R=, 335^{* *} *$} \\
\hline
\end{tabular}

${ }^{*} \mathrm{p} \leq 0.05,{ }^{* *} \mathrm{p} \leq 0.01$.

Para o fator Sugestões criativas, o tipo motivacional Autonomia apresentou-se como único preditor significativo. Todos os fatores de valores organizacionais explicaram 6\% da variância. Para o fator Ações Protetoras, os fatores que contribuíram significativamente foram Autonomia e Hierarquia, sendo que a explicação total do modelo foi de $8 \%$ da variância. Para o fator Criação de clima favorável no ambiente externo, Domínio e Autonomia apresentaram-se como preditores significativos e a explicação total foi de $23 \%$ da variância. Para Autotreinamento, os fatores Autonomia e Harmonia foram os preditores significativos e a explicação total do modelo foi de $5 \%$ da variância. Finalmente, para o fator Cooperação com os colegas, o tipo motivacional Autonomia foi o único preditor significativo e o modelo explicou $10 \%$ da variância.

\section{Dıscussão}

Os resultados apresentados indicam que os valores organizacionais predizem os comportamentos de civismo nas organizações. Os valores de Autonomia apresentaram-se como preditores de todos os comportamentos de civismo, sendo o principal preditor destes comportamentos. Os valores de Harmonia predizem unicamente o fator Autotreinamento; os valores de Hierarquia predizem Ações Protetoras; e os valores de Domínio predizem Criação de clima favorável à organização. Os pólos Conservação e Igualitarismo não apresentaram predição significativa para nenhum dos fatores de civismo, indicando pouca contribuição para o modelo estudado. 
O pólo Autonomia refere-se aos valores de inovação e expressa características de organizações que estimulam a inovação e a criatividade. Os comportamentos de Sugestões criativas implicam idéias originais e inovadoras para o ambiente de trabalho. Assim, esses comportamentos seriam uma forma de expressar esses valores organizacionais e, portanto, são enfatizados pela organização. Os comportamentos de Autotreinamento também levam à inserção de inovações no trabalho por meio da aprendizagem de novas habilidades e conhecimentos, sendo coerentes com os valores que promovem a busca de novas soluções para os problemas organizacionais. Pessoas que percebem a sua organização, valorizando a Autonomia, também tendem a emitir mais comportamentos de Criação de clima favorável à organização no ambiente externo e de Ações protetoras, pois as suas metas estão em consonância com as metas organizacionais: ao defender e proteger a organização, também estão sendo atendidas metas individuais. Além disso, as organizações, ao incentivar novas formas de agir, de executar o trabalho e de produzir, podem favorecer a cooperação com os colegas como uma forma de atingir essas metas.

O pólo Hierarquia enfatiza o respeito às chefias, às regras e normas organizacionais. Este pólo busca solucionar a necessidade de adequação indivíduo e grupo, pela hierarquização das relações. Segundo Tamayo (1999), existe uma familiaridade dos brasileiros com modelos hierárquicos que definem, com precisão, os papéis e as formalidades do relacionamento. Esses modelos proporcionam maior segurança aos indivíduos, pois explicitam os comportamentos sociais e organizacionais esperados e deixam pouca margem para a improvisação. Os comportamentos de Ações protetoras são comportamentos cada vez mais valorizados pelas organizações e, à medida que são estabelecidos como comportamentos esperados, o modelo hierárquico favorece a sua emissão.

O pólo Domínio expressa características de organizações que enfatizam a sua preponderância sobre as suas concorrentes e sobre o meio ambiente. Os aspectos valorizados são conquista de clientes, melhor posicionamento no mercado e ação arrojada. Os comportamentos de Criação de clima favorável à organização no ambiente externo são formas de expressar o domínio organizacional sobre o mercado por meio da divulgação das vantagens e méritos da organização.

O pólo Harmonia é teoricamente oposto ao Domínio, mas na pesquisa empírica realizada por Tamayo, Mendes e Paz (2000), ele não apresentou o antagonismo postulado. A harmonia expressa a tentativa, pela organização, de acomodamento harmonioso com a natureza e outras organizações. As empresas que valorizam a Harmonia buscam lidar com a necessidade de relacionar-se com o ambiente externo, não por meio da exploração, mas por meio de colaboração. Os comportamentos de Autotreinamento estariam associados à Harmonia, pois os indivíduos verificam que, ao cumprir esses comportamentos, é possível se 
posicionar com sucesso no mercado, valendo-se de uma interação harmoniosa com a natureza e outras organizações.

A literatura aponta que a cultura organizacional pode ser um determinante de relevo para a compreensão dos comportamentos de civismo. Os resultados encontrados nesta pesquisa reforçam a importância de elementos culturais na promoção desses comportamentos e indicam que os valores organizacionais guiam os comportamentos de civismo, como já apontado pelos trabalhos que relacionaram valores organizacionais e comportamento no trabalho (MEGLINO; RAVLIN; ADKINS, 1989; O’REILLY; CHATMAN; CALDWELL, 1991 apud WILPERT, 1995; SHERIDAN, 1992 apud WILPERT, 1995; TAMAYO, 1996).

\section{Conclusão}

O objetivo deste artigo era investigar o impacto dos Valores Organizacionais sobre os comportamentos de civismo nas organizações. Este objetivo foi alcançado por meio de pesquisa correlacional que apontou os valores organizacionais de Autonomia como os principais preditores de civismo nas organizações.

A literatura de civismo nas organizações apresenta que variáveis atitudinais como satisfação no trabalho, variáveis do contexto organizacional como percepção de justiça organizacional e variáveis individuais como valores pessoais são preditores desses comportamentos. O presente trabalho aponta a cultura organizacional como nova variável importante para os estudos dos comportamentos de civismo. É possível, porém, que a relação entre valores organizacionais e comportamento de civismo seja mediada por outras variáveis como políticas de recursos humanos e variáveis atitudinais já apontadas na literatura. Os seis pólos de valores organizacionais avaliados nesta pesquisa representam o núcleo da cultura organizacional. A contribuição isolada de cada um dos pólos é moderada. Por outra parte, os valores se mostraram preditores para todos os fatores de civismo e o valor preditivo do conjunto dos tipos motivacionais de valores é bastante importante. Este dado indica que o comportamento de civismo é tributário da cultura organizacional. Ele não é resultante de um único aspecto da cultura da empresa, mas de diversas forças culturais. Além dos determinantes culturais, os comportamentos de civismo nas organizações possuem diversos outros preditores, como se aponta na revisão de literatura. Modelos mais complexos que abarquem as variáveis mencionadas acima, podem ser necessários para a compreensão deste fenômeno. Outras pesquisas poderiam investigar também a adequação dos valores organizacionais aos valores individuais, já que a literatura tem apontado que esta adequação pode ser melhor preditor do que os valores isoladamente. 
Ao utilizar uma teoria ampla para a compreensão dos valores organizacionais que supera as dificuldades dos estudos anteriores, este estudo demonstra que os valores organizacionais são preditores importantes do comportamento organizacional, merecendo especial atenção por parte dos pesquisadores. Futuramente, pesquisas poderiam investigar a hipótese de que a adequação dos valores individuais aos valores organizacionais seria melhor preditor dos comportamentos do que os valores organizacionais.

Uma limitação do estudo pode ser o fato de que a medida dos Valores Organizacionais foi realizada, exclusivamente, a partir da percepção dos funcionários. Seria interessante considerar também os valores divulgados pela empresa e investigar os de sua diretoria. Além disso, pesquisas futuras poderiam utilizar amostra diferente para medir os Valores Organizacionais, evitando a contaminação nas respostas de civismo nas organizações.

Os resultados obtidos podem ser objeto de aplicações da gestão da cultura organizacional e, particularmente, dos valores organizacionais, quando se deseja desenvolver o comportamento de civismo na Organização. Os gestores interessados em promover os comportamentos de civismo, além de trabalhar as variáveis individuais apontadas na literatura, podem enfatizar os valores organizacionais associados a esses comportamentos como forma de assegurar melhores resultados para sua organização.

\section{Artigo recebido em 21.02.2003. Aprovado em 11.07.2004.}

\section{ReferênCIAS Bibliográficas}

\section{CHATMAN, J.A.}

Matching people and organization: selection and socialization in public accounting firms. Administrative Science Quarterly, Ithaca, v. 36, n. 3, p.459-484, sep. 1991.

\section{GEORGE, J.M.}

State or trait: effects of positive mood on prosocial behaviors at work. Journal of Applied Psychology, Washington, v. 76, n. 2, p.299 - 307, apr.1991.
GEORGE, J. M.;

BRIEF, A. P.

Feeling good-doing good: a conceptual analysis of the mood at work-organizational spontaneity relationship. Psychological Bulletin, Washington, v. 112, n.2, p.310 - 329, sep.1992.

KATZ, D.;

KAHN, R. L.

Psicologia social das organizações.

São Paulo: Atlas, 1974. 
LAMBERT, S. J.

Added benefits: the link between work-life benefits and organizational citizenship behavior. Academy of Management Journal, Briarcliff Manor, v.43, n. 5, p.801-815, oct.2000.

MEGLINO, B. M.;

RAVLIN, E. C.;

ADKINS, C, L.

A work approach to corporate culture: a field test of the value congruence process and its relationship to individual outcomes. Journal of Applied Psychology, Washington, v.74, n.3, p.424-432, june.1989.

\section{MOORMAN, R. H.}

Relationship between organizational justice and organizational citizenship behaviors: do fairness perceptions influence employee citizenship? Journal of Applied Psychology, Washington, v.76, n.6, p.845-855, dec.1991.

MOORMAN, R. H.;

BLAKELY, G L.

Individualism-collectivism as an individual difference predictor of organizational citizenship behavior. Journal of Organizational Behavior, Chichester, v.16, n.2, p.127-142, mar.1995.

MUNENE, J. C.

Not-on-seat: an investigation of some correlates of organizational citizenship behavior in Nigeria. Applied Psychology: An International Review, Oxford, v.44, n.2, p.111-122, Jan. 1995.

NORD, W. R.;

FOX, S.

The individual in organizational studies: the great disappearing act?
In: CLEGG, S.R.; HARDY, C.; NORD, W.R. Handbook of Organizational Studies, Londres: Sage, Cap.1.5, p.148-174, 1996.

O'REILLY, C.A.;

CHATMAN, J.A.

Organizational commitment and psychological attachment: the effects of compliance, identification, and internalization on prosocial behavior. Journal of Applied Psychology, Washington, v.71, n.3, p.492-499, aug.1986.

\section{ORGAN, D. W.;}

HUI, C.

Time pressure, type a syndrome, and organizational citizenship behavior: a field study replication of hui, organ, and crooker (1994). Psychological Reports, v.77, p.179-185, 1995.

ORGAN, D. W.;

KONOVSKY, M.

Cognitive versus affective determinants of organizational citizenship behavior. Journal of Applied Psychology, Washington, v.74, n.1, p.157-164, feb.1989.

ORGAN, D. W.;

LINGL,A.

Personality, satisfaction, and organizational citizenship behavior. The Journal of Social Psychology,Washington, v.135, n.3, p.339-350, june.1995.

ORGAN. D. W.;

RYAN, K.

A meta-analytic review of attitudinal and dispositional predictors of organizational citizenship behavior. Personnel Psychology, Durhan, v.48, n.4 p.775-802, dec./feb.1995. 
PEARCE, J.L.;

\section{GREGERSEN,H.B.}

Task interdependence and extrarole behavior: a test of the mediating effects of felt responsibility. Journal of Applied Psychology, Washington, v.76, n.6, p.838-844, dec.1991.

PODSAKOFF, P. M.;

AHEARNE, M.;

MACKENZIE, S. B.

Organizational citizenship behavior and the quantity and quality of work group performance. Journal of Applied Psychology, Washington, v.82, n.2, p.262-270, apr.1997.

PORTO, J. B.

Prioridades axiológicas e culturas regionais como preditores de civismo nas organizações. 1998. 115 f.. Dissertação (Mestrado em Psicologia Social e do Trabalho) - Instituto de Psicologia, Universidade de Brasília, Brasília.

PORTO, J.B.;

TAMAYO, A.

Prioridades axiológicas e regiões brasileiras: preditores de civismo nas organizações. Psicologia: Organizações e Trabalho, Florianópolis, v.2, n.1, p.31-57, jan./jun.2002.

Desenvolvimento e validação da escala de civismo nas organizações. Estudos de Psicologia, Natal, v.8, n.3, p.393-402, set./dez.2003.

\section{SCHWARTZ, S. H.}

Universals in the content and structure of values: theoretical advances and empirical tests in 20 countries. In ZANNA, M. P. (org.),
Advances in Experimental Social Psychology, v.25, Orlando: Academic, 1992. cap.1, p.1-65.

Are there universal aspects in the structure and contents of human values? Journal of Social Issues, Nova York, v.50, n.4, p.19-45, dec./ feb.1994.

Value priorities and behavior: applying a theory of integrated value systems. In: SELIGMAN, C., OLSON, J. M., ZANNA, M. P. (Org.). Psychology of Values: the ontario symposium. New Jersey: Lawrence Erlbaum Associate, v. 8. cap.1. p. 126, 1996.

A theory of cultural values and some implications for work. Applied Psychology: An International Review, Oxford, v.48, n.1, p.23-47, jan.1999.

SETTOON, R. P.;

BENNETT, N.;

LIDEN, R. C.

Social exchange in organizations: perceived organizational support, lider-member exchange, and employee reciprocity. Journal of Applied Psychology, Washington, v.81, n.3, p.219-227, june. 1996.

\section{SHORE, L. M.;}

WAYNE, S. J.

Commitment and employee behavior: caparison of affective commitment and continuance commitment with perceived organizational support. Journal of Applied Psychology, Washington, v.78, n.5, p.774-780, oct.1993. 
SKARLICKI, D. P.;

LATHAM, G. P.

Increasing citizenship behavior within a labor union: a test of organizational justice theory. Journal of Applied Psychology, Washington, v.81, n.2, p.161 - 169, apr.1996.

SIQUEIRA, M. M. M.

Antecedentes de comportamentos de cidadania organizacional: a análise de um modelo pós-cognitivo. 1995. Tese (Doutorado em Psicologia) Instituto de Psicologia, Universidade de Brasília, Brasília.

SMITH, C.A.;

ORGAN, D. W.;

NEAR, J. P.

Organizational citizenship behavior: its nature and antecedents. Journal of Applied Psychology, Washington, v.68, n.4, p.653-63, nov.1983.

TAMAYO, A.

Valores organizacionais. In: TAMAYO, A.; BOGES-ANDRADE, J. E.; CODO, W. (org) Trabalho, Organizações e Cultura. Coletâneas da ANPEPP, 1996a.

Valores organizacionais: sua relação com satisfação no trabalho, cidadania organizacional e comprometimento afetivo. Revista de Administração, São Paulo, v.33, n.3, p.56-63, jul./ set.1996b.

Valores e clima organizacional. In: PAZ, M. G. T.; TAMAYO, A. (org.) Escola, Saúde e Trabalho: estudos psicológicos. Brasília: Universidade de Brasília, 1999.
TAMAYO, A.;

MENDES, A. M.;

PAZ, M. G. T.

Inventário de valores organizacionais.

Estudos de Psicologia, Natal, v.5, n.2, p.289-315, maio/ago.2000.

TAMAYO, A.;

GONDIM, M. G. C.

Escala de valores organizacionais.

Revista de Administração, São Paulo, v.31, n.2, p.62-72, abr./jun.1996.

TAMAYO, A. et al.

Prioridades axiológicas, tempo de serviço e cidadania organizacional. Psicologia: Teoria e Pesquisa, Brasília, v.14, n.1, p.30-35, jan./ mar.1998.

VANDYNE, L.;

CUMMINGS, L. L.;

PARKS, J. M.

In pursuit of construct and definitional clarity (a bridge over muddied waters). In: CUMMINGS, L. L.; STAW, B. M. (org.). Research in Organizational Behavior. V. 17. England: Jai Press Inc, 1995. cap.4. p. 215-285.

WAYNE, S. J.;

GREEN, S.A.

The effects of leader -member exchange on employee citizenship and impression management behavior. Human Relations, Nova York, v.46, n.12, p.1431-1440, dec.1993.

WILPERT, B.

Organizational behavior. In: ROSENZWEIG, M.R.; PORTER, L.W. (Eds.), Annual Review of Psychology, California, v.46, p.59-90, 1995. 
WITT, L. A.

Exchange ideology as a moderator of job attitudes - organizational citizenship behaviors relationships. Journal of Applied Social Psychology, Florida, v.21, n.18, p.1490 - 501, set.1991.
WITT, L.A.;

WILSON, J.W.

Moderating effect of job satisfaction on the relationship between equity and extra-role behaviors. The Journal of Social Psychology, Washington, v.131, n.2, p.247-252, abr.1990. 